\title{
Author Correction: Regionalization of the axial skeleton predates functional adaptation in the forerunners of mammals
}

Katrina E. Jones DiD, Sarah Gonzalez, Kenneth D. Angielczyk and Stephanie E. Pierce (D)

Correction to: Nature Ecology \& Evolution https://doi.org/10.1038/s41559-020-1094-9, published online 3 February 2020.

In the version of this Article originally published, in Fig. 1, the colour legend in the middle-left panel was incorrect. 'Dorsiflexion' was originally labelled red but should have been grey; 'Lateroflexion' was originally labelled blue but should have been green; 'Ventroflexion' was originally labelled green but should have been orange. This has now been corrected.

Published online: 20 February 2020

https://doi.org/10.1038/s41559-020-1151-4

(C) The Author(s), under exclusive licence to Springer Nature Limited 2020 